\title{
Amazing candle flames
}

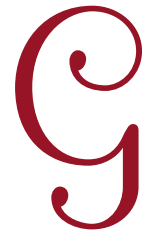

ranted: a candle flame is a lousy source of light. For an energy user of some $100 \mathrm{~W}$, its light production doesn't even come close to any modern light source. But other than that, it represents an ingenious piece of technology. Before going into details, we should realize that, when talking about flames, we are talking about chemical reactions in the gas phase. We can even illustrate this in a simple way by blowing out a candle, and re-lighting it by sticking a burning match into the stream of smoke above the hot wick. So, we cannot simply light a chunk of candle wax by a match, because its vapour pressure is far too low. Take paraffin, by far the most common wax used in candle production. It consists of a mixture of hydrocarbons, for example $\mathrm{C}_{\mathrm{n}} \mathrm{H}_{2 \mathrm{n}+2}$ with n typically around 22 to 25. Such molecules have vapour pressures at ambient temperature far below $10^{-6}$ bar, much too low to be ignited and fortunately - low enough for the candles to be stored almost indefinitely. So, for igniting paraffin we

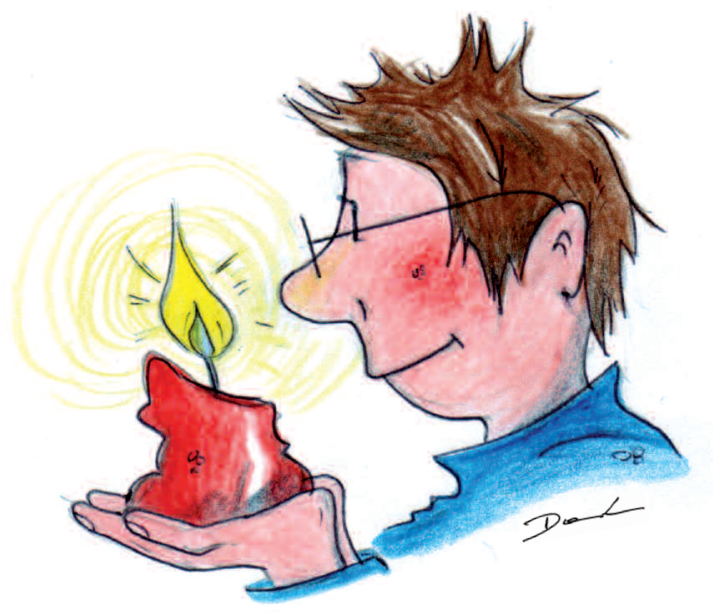

the flame is extinguished. Its construction has a decisive impact on the performance of the candle, including the stance of the wick and its ability to self trim. It may contain a zinc or tin core to help it stay upright when the surrounding wax liquefies.

The operation of the candle teaches us, in passing, that the heat of combustion is much greater than the heat of melting and the heat of vaporization combined. It is one of the elementary physics lessons hidden in a candle. Obviously, the operation of the candle depends on natural convection to remove the combustion products and supply fresh oxygen. Indeed, in microgravity a lit candle burns only for a short while before extinguishing by lack of oxygen. Here is another physics lesson: diffusion at ambient pressure is a very slow process.

The flame itself represents a series of steps: vaporization of the wax, pyrolysis into gaseous hydrocarbon fragments and solid carbon particles ('soot') and, finally, burning of the carbon particles in the luminous cone which is the whole purpose of the candle to begin with. In must get closer to its boiling point, which is somewhere in the range of 350 to $430{ }^{\circ} \mathrm{C}$.

This is precisely what we achieve by having a wick with some paraffin absorbed. Its heat capacity is so small that its temperature can be raised by a burning match in just a second.

The wick is the heart of the candle. It not only melts the wax just below it, it also acts as a fuel pump by drawing up liquid wax by capillary action, thereby regulating the flame. And if we look carefully after lighting a candle, we notice that the flame is large at first, then gets smaller by lack of fuel, and only burns in its full glory once it manages to melt a layer of wax. The wick is usually made of braided cotton threads, treated with some inorganic compound to prevent afterglow once case of incomplete combustion of these C-particles for example, if there is lack of oxygen, or if a gust of wind decreases the flame's temperature to below $1000^{\circ} \mathrm{C}$ - the flame will emit soot and spoil the fun.

The temperature in the luminous cone is around $1200^{\circ} \mathrm{C}$. Now it becomes clear just why a candle is such an inefficient light source. Not only is more than $80 \%$ of the heat convected up and away from the flame. The remaining 20\% does not provide very efficient lighting either. If we assume that the burning carbon particles at $1200^{\circ} \mathrm{C}$ behave like a Planck radiator, Wien's law tells us that its emission peak is at approximately $2 \mu \mathrm{m}$ wavelength. Given the narrow eye sensitivity curve centered around $0.5 \mu \mathrm{m}$, the conclusion is inevitable. Candles provide interesting science, but hardly any light. 